year at school, as well as to their parents. A few genetic clinics are necessary to provide this service; ophthalmological support is essential for an accurate diagnosis, itself a prerequisite for meaningful genetic counselling.

The "new genetics," with prenatal diagnosis by chorion biopsy of genetically determined disorders, has dramatically changed the prospects of secondary prevention. Among the conditions that may now be diagnosed early in pregnancy are $\mathrm{X}$ linked retinitis pigmentosa, ${ }^{9}$ choroideraemia, ${ }^{10}$ and retinoblastoma. ${ }^{11}$ This list should increase over the next few years, with additional autosomal recessive, autosomal dominant, and $\mathrm{X}$ linked conditions. Hence secondary prevention of genetically determined diseases will become increasingly important. This is yet another reason why genetic counselling should be made available to all visually handicapped children and their families.

BARRIE JAY

Professor of Clinical Ophthalmology,

University of London,

Moorfields Eye Hospital,

London ECIV 2PD

1 Sorsby A. The causes of blindness in England and Wales. London: HMSO, 1950.

2 Sorsby A. The incidence and causes of blindness in England and Wales 1948-1962. London: HMSO, 1966.

3 Sorsby A. The incidence and causes of blindness in England and Wales 1963-68. London: HMSO, 1972.

4 Department of Health and Social Security. Blindness and partial sight in England 1969-1976. London: HMSO, 1979. (DHSS reports on public health and medical subjects No 129.)

5 Fraser GR, Friedmann AI. The causes of blindness in childhood. Baltimore: Johns Hopkins Press, 1967.

6 Schappert-Kimmijser J. Causes of severe visual impairment in children and their prevention. Doc Ophthalmol 1975;39:213-341.

Phillips CI, Levy AM, Newton M, Stokoe NL. Blindness in schoolchildren: importance of heredity, congenital cataract and prematurity. Brit $\mathcal{f}$ Ophthalmol (in press).

heredity, congenital cataract and prematurity. Brit $f$ Ophthalmol (in press). UK 1978;98:311-2.

9 Bhattacharya SS, Wright AF, Clayton JF, et al. Close genetic linkage between X-linked retinitis pigmentosa and a restriction fragment length polymorphism identified by recombinant DNA probe L1.28. Nature 1984;309:253-5.

10 Nussbaum RL, Lewis RA, Lesko JG, Ferrell R. Choroideremia is linked to the restriction fragment length polymorphism DXYS1 at Xq13-21. Am f Hum Genet 1985;37:565-75.

11 Sparkes RS, Murphree AL, Lingua RW, et al. Gene for hereditary retinoblastoma assigned to human chromosome 13 by linkage to esterase D. Science 1983;219:971-3.

\section{Laboratory control of oral anticoagulants}

A several fold variation in the mean warfarin dose in different geographical locations has been reported in a recent international survey. ${ }^{1}$ The main cause of the variation was the tissue thromboplastin in the test for the prothrombin time. North American centres, which used rabbit brain thromboplastin almost exclusively, gave more warfarin than centres elsewhere, which used human brain reagents.

This problem was resolved in Britain with the introduction in 1969 of the national system for anticoagulant control by the British Society for Haematology. A single reagent, British comparative thromboplastin, was adopted as the national reference preparation and was linked to a national system of reporting the British ratio. British comparative thromboplastin was a designated batch of the routine reagent, Manchester comparative thromboplastin, which until recently was employed by over $95 \%$ of British hospitals.

This human brain tissue extract had to be withdrawn in early 1986 because of the possible risk of contamination by human immunodeficiency virus tissue from the central nervous system. Other thromboplastin reagents are now again being used to estimate the prothrombin time in British hospitals. Does this matter or has the problem been solved by the prothrombin time standardisation system based on international normalised ratios (INR)? These ratios were introduced recently by the World Health Organisation ${ }^{23}$ and are derived from calibrations of routine thromboplastin reagents against an international reference preparation. The validity of the system has been confirmed in international collaborative studies. ${ }^{46}$

The international normalised ratio is defined as the prothrombin time ratio that would have been obtained if the original WHO international reference preparation had been used. It depends on the international sensitivity index (ISI), derived from calibrating the commercial thromboplastins against an international reference preparation on the results of prothrombin times of blood from controls and patients stabilised with long term treatment with coumarin. The resulting index quantifies the responsiveness of the commercial thromboplastin to the coumarin defect in terms of the primary international reference preparation (defined as $1 \cdot 0)$.

Surveys by the UK External Quality Assessment Scheme in Blood Coagulation have shown, however, that different international normalised ratios are obtained with the various reagents on the same test samples. There are various possible explanations. Some manufacturers are apparently not yet calibrating their reagents correctly. Secondly, coagulometers are now used in nearly half of British hospitals, and some of these may cause serious deviations from the mean result gained using the same reagent with a manual technique.

Calibration of thromboplastins are performed on samples taken from patients stabilised on long term treatment. Hospital patients in the early induction stages of treatment must not be included. In the first 7-10 days of warfarin treatment the international normalised ratios appear less dependable with some reagents because of their varying responses to depression of individual vitamin $K$ dependent clotting factors. ${ }^{?}$

The problems will be resolved only by manufacturing thromboplastin reagents showing better sensitivity to the coumarin induced defect, ideally giving international sensitivity index values between $1 \cdot 0$ and $1 \cdot 2$. Few commercial reagents would qualify at present, but the accurate implementation of the international system by the manufacturers might provide them with the necessary insight and impetus to improve the quality of their reagents.

In the mean time British hospitals should report international normalised ratios with all prothrombin time results used for anticoagulant control, employ a reagent with a low international sensitivity index, and participate regularly in the UK National External Quality Assessment Surveys in Blood Coagulation.

Director,

UK Reference Laboratory for

Anticoagulant Reagents and Control,

Withington Hospital,

Manchester M20 8LR

1 Poller $\mathrm{L}$, Taberner DA. Dosage and control of oral anticoagulants: an international survey. $\mathrm{Br} f$ Haematol 1982;51:479.

Kirkwood TBL, Lewis SM. Requirements for thromboplastins and plasma used to control ora anticoagulant therapy. WHO Tech Rep Ser 1983;687:81-99.

3 Expert Committee on Biological Standardisation. Thiry-fourth report. WHO Tech Rep Ser 1984;700:18-9.

4 Hermans J, van den Besselaar AMPH, Loeliger EA, van der Velde EA. A collaborative calibration study of reference materials for thromboplastins. Thromb Haemost (Stuttg) 1983;50:712-7.

5 Thomson JM, Tomenson JA, Poller L. The calibration of the second primary international reference preparation for thromboplastin (thromboplastin, human, plain, coded BCT/253). Thromb Haemost (Stuttg) 1984;52:336-42.

6 Thomson JM, Darby KV, Poller L. Calibration of BCT/441 the ICSH reference preparation fo thromboplastin. Thromb Haemost (Stutg) 1986;55:379-82.

7 Poller L. Progress in standardisation in anticoagulant control. Haematology Reviews 1987;1:225-41. 